\title{
Transforming capacity of two novel genes JS-1 and JS-2 located in chromosome $5 p$ and their overexpression in human esophageal squamous cell carcinoma
}

\author{
SARWAT FATIMA ${ }^{1}$, CHUNG H. CHUI ${ }^{1-4}$, WING K. TANG ${ }^{1}$, KIN S. HUI ${ }^{1}$, HO W. AU ${ }^{1}$, WING Y. LI ${ }^{1}$, \\ MEI M. WONG ${ }^{1}$, FILLY CHEUNG ${ }^{1}$, S.W. TSAO ${ }^{5}$, KING Y. LAM ${ }^{8}$, PHILIP S.L. BEH ${ }^{6}$, JOHN WONG ${ }^{7}$, \\ SIMON LAW ${ }^{7}$, GOPESH SRIVASTAVA ${ }^{6}$, KWOK P. HO ${ }^{1}$, ALBERT S.C. CHAN ${ }^{1-3}$ and JOHNNY C.O. TANG ${ }^{1-3,6}$ \\ ${ }^{1}$ Department of Applied Biology and Chemical Technology, ${ }^{2}$ Central Laboratory, \\ Institute of Molecular Technology for Drug Discovery and Synthesis, The Hong Kong Polytechnic University, \\ Hong Kong; ${ }^{3}$ State Key Laboratory of Chinese Medicine and Molecular Pharmacology, Shenzhen; \\ ${ }^{4}$ Department of Medicine and Therapeutics, Prince of Wales Hospital, The Chinese University of Hong Kong; \\ Departments of ${ }^{5}$ Anatomy, ${ }^{6}$ Pathology, and ${ }^{7}$ Surgery, The University of Hong Kong, Hong Kong, \\ P.R. China; ${ }^{8}$ School of Medicine, Griffith University, Queensland, Australia
}

Received September 2, 2005; Accepted October 3, 2005

\begin{abstract}
Esophageal squamous cell carcinoma (ESCC) has a high mortality rate and geographic differences in incidence. Previous studies of comparative genomic hybridization (CGH) showed that chromosomal $5 p$ is frequently amplified in cell lines and primary ESCC of Hong Kong Chinese origin. In this report, attempt was made to study two novel genes, named as JS-1 and JS-2, which are located in chromosome 5p15.2 and are 5 ' upstream to $\delta$ catenin for their roles in molecular pathogenesis of ESCC. Eleven cell lines, 27 primary ESCC cases and multiple human tissue cDNA panels (MTC) of digestive system were studied for the expression level of JS-1 and JS-2 by RT-PCR. The full-length cDNA sequences of JS-1 and JS-2 were determined from a non-tumor esophageal epithelial cell line by $3^{\prime}$ and $5^{\prime}$ rapid amplification of cDNA ends (RACE). The transforming capacity of JS-1 and JS-2 was also investigated by transfecting NIH 3T3 cells with the expression vector pcDNA3.1(-) cloned with the full coding sequences and it was followed by the study of foci formation of the transfected cells under confluence growth and the anchorage-independent growth in soft agar. Forty-five percent $(5 / 11)$ and $18 \%(2 / 11)$ of the ESCC cell lines showed overexpression of JS-1 and JS-2 respectively, while 55\% (15/27) and $14 \%(3 / 22)$ primary ESCC cases showed overexpression of JS-1 and JS-2 respectively. JS-1 overexpression was most common in patients with stage II ESCC $(6 / 27 ; 22 \%)$ whereas
\end{abstract}

Correspondence to: Dr Johnny C.O. Tang, Department of Applied Biology and Chemical Technology, The Hong Kong Polytechnic University, Hung Hom, Hong Kong, P.R. China

E-mail: bccotang@inet.polyu.edu.hk

Key words: esophageal squamous cell carcinoma, gene overexpression, transforming capacity, tumorigenicity
JS-2 was only overexpressed in a dysplastic lesion (1/22; 4\%) and stage III tumors $(2 / 22 ; 9 \%)$. The expression levels of JS-1 and JS-2 are both low in normal esophageal tissues. Overexpression of JS-1 in NIH 3 T3 cells caused foci formation in confluence growth and colony formation in soft agar but not for JS-2. A high grade sarcoma was formed in the athymic nude mice when NIH 3 T3 cells overexpressing JS-1 were injected subcutaneously. Our results thus indicate that the frequent overexpression of JS-1 in ESCC and its transforming capacity in normal cells may play a critical role in the molecular pathogenesis of ESCC. The present study also forms the ground work for further identification of novel mechanisms of molecular carcinogenesis in ESCC and other cancers.

\section{Introduction}

Esophageal squamous cell carcinoma (ESCC) is an aggressive cancer that is characterized by a high mortality rate and geographic differences in incidence (1). The incidence of ESCC was reported to be particularly high in northern China and northern Iran (2). The incidence rate varies from 130 per 100,000 people in endemic regions (Linxian, China and Kazakhstan) to 4 per 100,000 people in USA (3). Despite advances in multimodality treatments, the 5-year survival rate of ESCC remains < $10 \%$ (4). The etiology of ESCC has been studied in detail and the risk factors include alcohol and tobacco consumption, dietary intake of nitrosamines, fermented food, vitamin and mineral deficiencies, and a poor diet in fresh fruits and vegetables (5). Moreover, the postulated correlations of human papilloma virus (HPV) infection to incidence of ESCC vary geographically with higher rates observed in high risk areas than in low risk areas (6). It has also been reported that many oncogenes and tumor suppressor genes are closely related to the molecular pathogenesis of ESCC, such as $c-m y c$, cyclin D1, pRB and p53 (5), nevertheless the complete picture of the molecular and genetic 
bases for the carcinogenesis of ESCC still remain largely unknown. Thus it will be of great value to identify the novel molecular targets for understanding the molecular carcinogenic mechanisms of the disease. This is helpful not only for the possible improvement of the current therapeutic protocols, but also for the early detection and prognosis of this disease.

The work of the human genome project (HGP) has resulted in a vast amount of genomic sequences and the functional roles of some of the predicted genes in particular chromosomal regions remain uncertain. Thus it will be significant to explore the functional roles of these novel genes in order to understand the possible involvement of these genes in the pathogenesis of various diseases. Previous studies on ESCC using comparative genomic hybridization (CGH) showed that the genomic amplification of chromosome $5 \mathrm{p}$ region is a common event (4). One target of our investigation is to understand the roles of candidate genes located within the minimum overlapping chromosomal region 5p15.2 in the molecular carcinogenesis of ESCC. The high level genomic amplification of this chromosomal region has also been observed in ESCC cases of Hong Kong Chinese origin (4). Thus the genomic amplification of this region may suggest the possible overexpression of candidate gene(s) which may be relevant to the molecular carcinogenesis of ESCC. For the first part of our study as reported in this study, we have studied the expression of two novel transcripts which have not been investigated before in ESCC and other cancers, and they are located $5^{\prime}$ upstream to the $\delta$ catenin gene in the chromosome $5 \mathrm{p} 15.2$ region. The overexpression of $\delta$ catenin has been implicated in a few cancers, e.g. gliomas (7) and prostate cancer (8), thus it will be of great value to understand the roles of the nearby genes in relation to their roles in molecular pathogenesis. We have established the full-length cDNAs of the two novel genes, JS-1 and JS-2, to study their overexpression in ESCC and their transforming capacity when they are overexpressed in normal cells. The overall results of the present study would add to our knowledge about the importance of differentially expressed genes in chromosome $5 \mathrm{p}$ region that could play a role in the molecular carcinogenesis of ESCC.

\section{Materials and methods}

ESCC cell lines and tissues. Eleven ESCC cell lines, SLMT-1 (9), HKESC-3 (10), and KYSE 30, 70, 140, 150, 180, 410, $450,510,520$ (11) were used in the present study. SLMT-1 and HKESC-3 cell lines were kindly provided by Professor Gopesh Srivastava of the Department of Pathology, The University of Hong Kong. The KYSE series of cell lines were purchased from DSMZ (Braunschweig, Germany). A HPV E6E7 immortalized non-tumor esophageal epithelial cell line (NE3) was also included in the present study which was kindly provided by Professor George S.W. Tsao of Department of Anatomy, The University of Hong Kong. The non-tumorigenic nature of NE3 was proven by the subcutaneous injection of $1 \times 10^{6} \mathrm{NE} 3$ cells into each of five athymic nude mice with no tumor formation. All ESCC cell lines and NE3 were cultured in DMEM (Dulbecco's modified Eagle's medium; Gibco) with $10 \%$ fetal bovine serum (FBS; Gibco) and
KSFM (keratinocyte serum-free complete medium; Gibco) respectively. All the cell lines were maintained in $37^{\circ} \mathrm{C}$ with $5 \% \mathrm{CO}_{2}$. Twenty-seven ESCC tissue specimens and their corresponding non-tumor tissues at least $5 \mathrm{~cm}$ away from tumors were used in the present study and were obtained by surgical resection from ESCC patients at the Queen Mary Hospital, Hong Kong between 1990 and 1998. All the ESCC specimens studied had $>80 \%$ viable tumor cells as shown by histological examination. Tissue specimens were snap-frozen in liquid nitrogen and stored in $-70^{\circ} \mathrm{C}$ until used.

RNA extraction and reverse transcription. Total RNA was extracted from ESCC cell lines, frozen ESCC tumor tissues and their corresponding non-tumor esophageal epithelial tissues using TRIzol (Invitrogen)/chloroform method according to the manufacturer's protocol. RNA $(1.5 \mu \mathrm{g})$ was used to synthesize cDNA in a $20 \mu 1$ reaction mixture containing, $5 \mathrm{mM}$ $\mathrm{MgCl}_{2}, 1 \mathrm{mM}$ of each dNTP, $2.5 \mu \mathrm{M}$ oligo d(T) $)_{16}$ primers, 20 units of RNase inhibitor (Applied Biosystems) and 50 units of MuLV reverse transcriptase (Applied Biosystems) at $42^{\circ} \mathrm{C}$ for $1 \mathrm{~h}$ followed by $95^{\circ} \mathrm{C}$ for $10 \mathrm{~min}$.

Rapid amplification of cDNA ends (RACE). Total RNA sample of non-tumor esophageal epithelial cell line (NE3) was used for the RACE study to determine the full-length transcripts of JS-1 and JS-2 using the 5'/3' RACE Kit (Roche). Fig. 1A and $\mathrm{B}$ show the positions of primers used in the present study of JS-1 and JS-2 respectively. For the 3' RACE study, the first cDNA strands were synthesized from total RNA using olido dT anchor primer (5'-GAC CAC GCG TAT CGA TGT CGA CTT TTT TTT TTT TTT TTV-3'; V=A, C or G) and were purified using QIAX II gel extraction kit (Qiagen). The subsequent amplification of the purified cDNA was done using PCR anchor primer (5'-GAC CAC GCG TAT CGA TGT CGA C-3') and 8809-i (5'-GTG GCT GAA AAC AAG AAA TG-3') for the study of JS-1 or the 9691-f (5'-TCT TTG GTC CAT AAA TGG TG-3') for the study of JS-2. For the 5' RACE study, the first strand cDNA was synthesized from the total RNA by using the primer 8809-e (5'-ATC ATC AAA TGA TGG ACA GC-3') for JS-1 study or 9691-i (5'AGC AAT AAC TCG TGC ATC AT-3') for JS-2 study. The synthesized cDNA was then purified using the QIAEX II gel extraction system (Qiagen). The purified cDNA was then tailed with dATP and terminal transferase and PCR amplification was done using the oligo dT anchor primer and 8809-f (5'-CCA CTC AGG GAA GAT AGA CC-3') for JS-1 or 9691-h (5'ATC CTC AAG TTC ACG TTC AA-3') for JS-2. The nested PCR amplification of the first PCR was followed using PCR anchor primer and the 8809-g (5'-AGT CTG GAA CAA TGG TTG TG-3') for JS-1 or 9691-g (5'-ACT GCT GTG AAC CCT TTC TT-3') for JS-2. The PCR products were then electrophoresed in $2 \%$ agarose gel and visualized under UV.

PCR analysis on human ESCC specimens and the corresponding non-tumor tissues. Total RNA was extracted from ESCC cell lines, frozen ESCC tumor tissues and their corresponding non-tumor esophageal epithelial tissues as described in the previous section using TRIzol (Invitrogen)/ chloroform method. One seventh of the total RT-PCR mixture was amplified in a $20 \mu \mathrm{l}$ reaction containing $1 \mu \mathrm{M}$ of each 
A

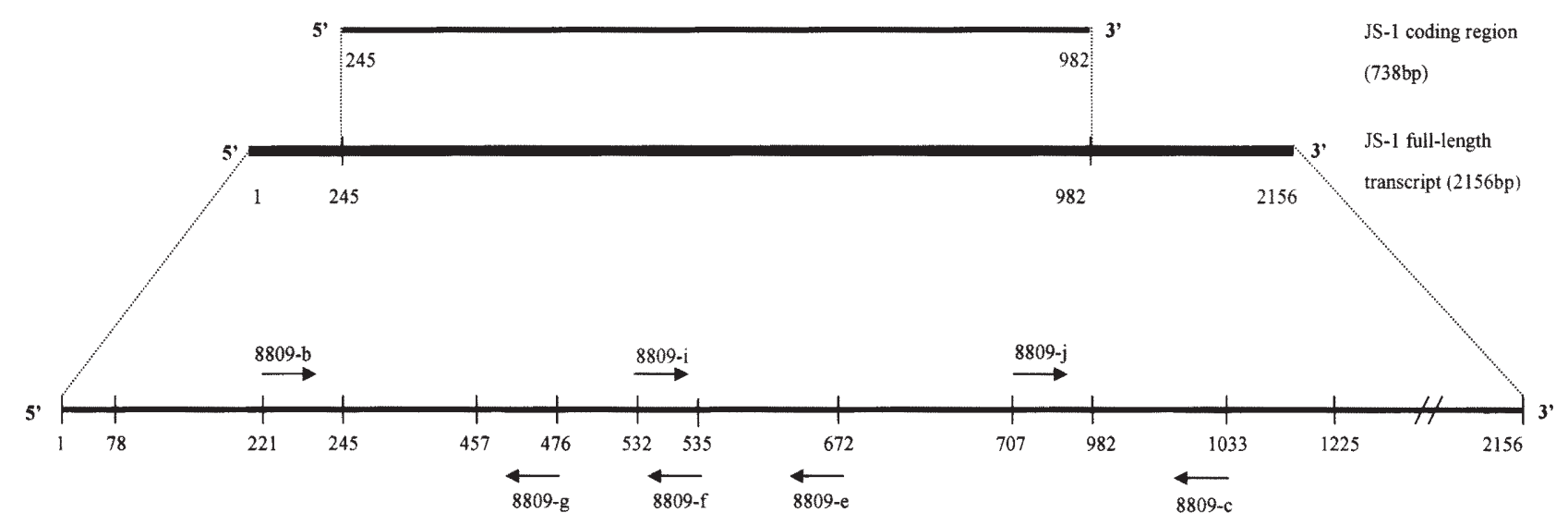

B

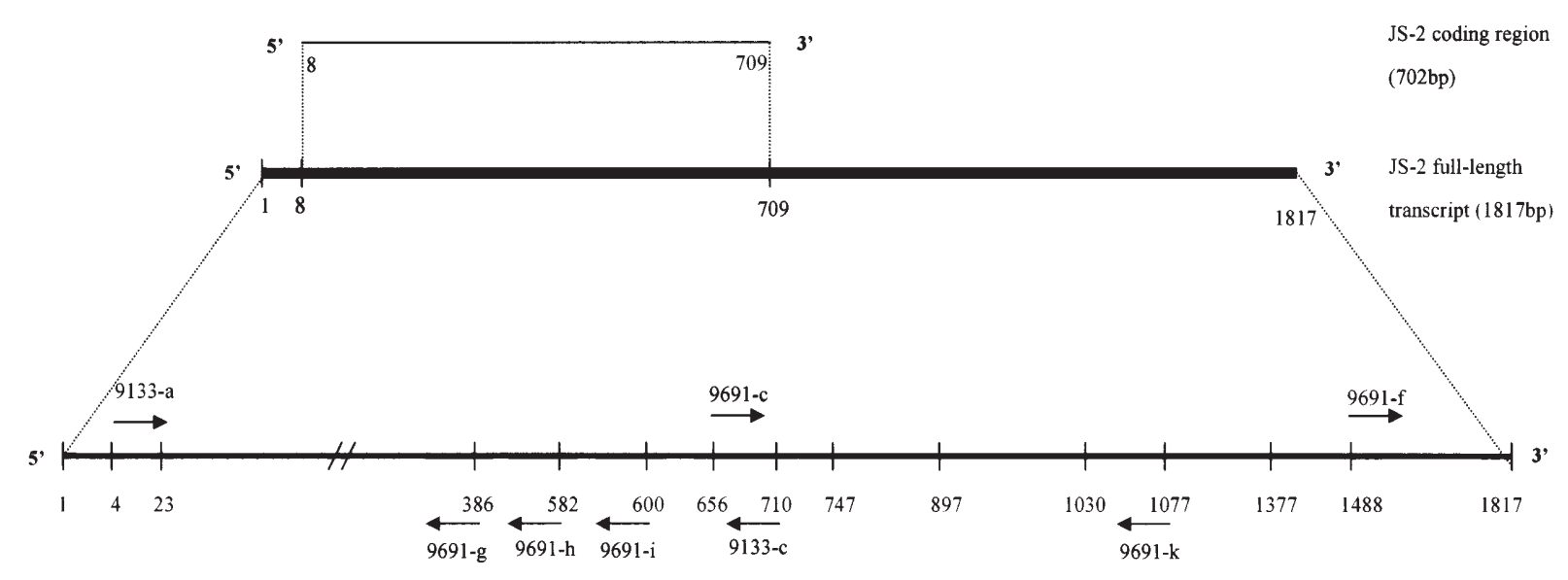

C

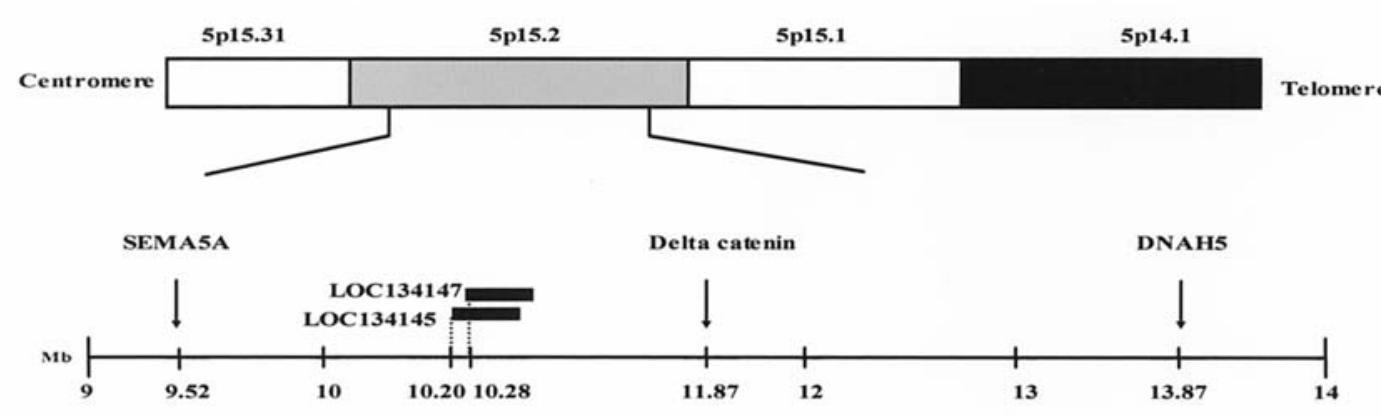

Figure 1. Schematic diagrams showing the positions of primers for (A) JS-1 and (B) JS-2 studies. The positions of primers (arrows) are numbered according to the full-length cDNA sequences produced from 5' RACE and 3' RACE analysis (see Materials and methods). (C) The chromosomal positions of JS-1 and JS-2 genes relative to the known genes on chromosome 5p15.2. JS-1 and JS-2 are located at LOC134147 and LOC134145 respectively which are 5' upstream to $\delta$ catenin gene. The diagrams are not drawn to scale.

primer, 1 unit of Taq polymerase (Promega), $0.2 \mathrm{mM}$ of each dNTP, $2 \mathrm{mM} \mathrm{MgCl}$ and the supplied PCR buffer $(50 \mathrm{mM}$ Tris-HCl, $100 \mathrm{mM} \mathrm{NaCl}, 0.1 \mathrm{mM}$ EDTA, $1 \mathrm{mM}$ DTT, 50\% glycerol and $1 \%$ Triton X-100). PCR was performed at initial denaturation at $95^{\circ} \mathrm{C}$ for $5 \mathrm{~min}$ followed by 35 cycles of denaturation for $1 \mathrm{~min}$, annealing for $1 \mathrm{~min}$ at $50^{\circ} \mathrm{C}$ and $47^{\circ} \mathrm{C}$ for JS-1 and JS-2 genes respectively and extension at $72^{\circ} \mathrm{C}$ for $1 \mathrm{~min}$, followed by a final extension at $72^{\circ} \mathrm{C}$ for $6 \mathrm{~min}$. The primers used to amplify the JS- 1 and JS- 2 transcripts to study the expression level of the two genes are as follows: for JS-1, the primers are 8809-j (5'-TAT GGC ATT GTC AAG GAT TC-3') and 8809-c (5'-AGC AAA TTT TGG GAT GAA AG-3'). For JS-2, the primers are 9691-c (5'-ACA CAG TGT GGG CAT ATG AT-3') and 9691-k (5'-TAT CGA GGC 
ATT AAG CCA TA-3'). Expression of ß-actin and glyceryl aldehyde-3-phosphate dehydrogenase $(\mathrm{GAPDH})$ were used as internal controls. For $B$-actin the primers are: sense 5'GTG GGC CGC TCT AGG CAC CAA-3' and antisense 5'CTC TTT GAT GTC ACG CAC GAT TTC-3' (Clontech). For GAPDH the primers are: GAPDH 1 5'-TGA AGG TCG GAG TCA ACG GAT TTG GT-3' and GAPDH 2 5'-CAT GTG GGC CAT GAG GTC CAC CAC-3' (Clontech). The PCR products were then electrophoresed in $1.5 \%$ agarose gel and visualized under UV. The intensity of PCR products was measured using Quantity One (Bio-Rad) gel image analysis system. The signal for each target PCR product was standardized against that of the $B$-actin PCR product from each sample. JS-1 and JS-2 mRNA expression levels were calculated using the formula [(JS-1 or JS-2/ß-actin, tumor)]/ [(JS-1 or JS-2/ß-actin, paired non-tumor)] as previously described (12).

Expression of JS-1 and JS-2 mRNA in gastrointestinal system. Expression of JS-1 and JS-2 was determined by RT-PCR study, as described in the previous section, on multiple tissue cDNA (MTC) panel (Clontech) of the human digestive tract that includes 10 separate gastrointestinal organs comprising the whole esophagus, stomach, duodenum, ileocecum, jejunum, colon ascending, colon transverse, colon descending, rectum and liver. For every PCR reaction, cDNA from each sample of the panel was amplified at initial denaturation at $95^{\circ} \mathrm{C}$ for $5 \mathrm{~min}$ followed by 35 cycles of denaturation for $1 \mathrm{~min}$, annealing for $1 \mathrm{~min}$ at $50^{\circ} \mathrm{C}$ and $47^{\circ} \mathrm{C}$ for JS- 1 and JS-2 genes respectively and extension at $72^{\circ} \mathrm{C}$ for $1 \mathrm{~min}$, followed by a final extension at $72^{\circ} \mathrm{C}$ for $6 \mathrm{~min}$. $\beta$-actin expression level was used to normalize the cDNA amount in each reaction as described in the previous section.

Preparation of constructs for expression study. With reference to the results of the RACE study, the full-length cDNA sequences of JS-1 and JS-2 were worked out (Fig. 3). The coding sequences of the two genes were produced from the cDNA of NE3 by PCR using primers 8809-b (5'-ACA AGC CCG ACT TAA ATC TC-3') and 8809-c (5'-AGC AAA TTT TGG GAT GAA AG-3') for JS-1 or primers 9133-a (5'-CGC GAT GGA GGG AGG AG-3') and 9133-c (5'-AAG TTT ATG CTT GAA TGG GCA GCT-3') for JS-2 (Fig. 1A and B). The PCR products were purified using the QIAEX II gel extraction system (Qiagen) and were cloned into pGEM-T Easy vector (Promega) and then subcloned into pcDNA3.1(-) vector (Invitrogen) according to the manufacturer's protocols. The sequences of the cloned regions were verified by DNA sequencing using ABI 310 Genetic Analyzer (Applied Biosystems) to ensure no cloning artifact was induced.

Transfection of NIH 3 T3 cells. NIH 3T3 cells were cultured in DMEM medium supplemented with $10 \%$ FBS. Subconfluent NIH 3 T3 cells $\left(3 \times 10^{5}\right.$ cells seeded in triplicate within each 6-well plate) were transfected with $1 \mu \mathrm{g}$ of the following plasmids: a) an empty vector of pcDNA3.1(-) as a negative control; b) pcDNA3.1-JS-1 or pcDNA3.1-JS-2 constructs; c) pcDNA3.1-H-ras V12 construct as a positive control (13), which was kindly provided by Dr L. Cao of the Department of Microbiology, The University of Hong Kong. NIH 3T3 cells
JS-1
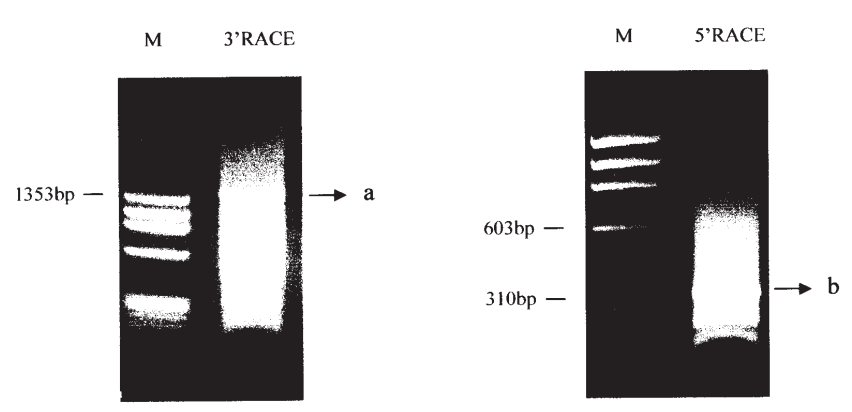

JS-2
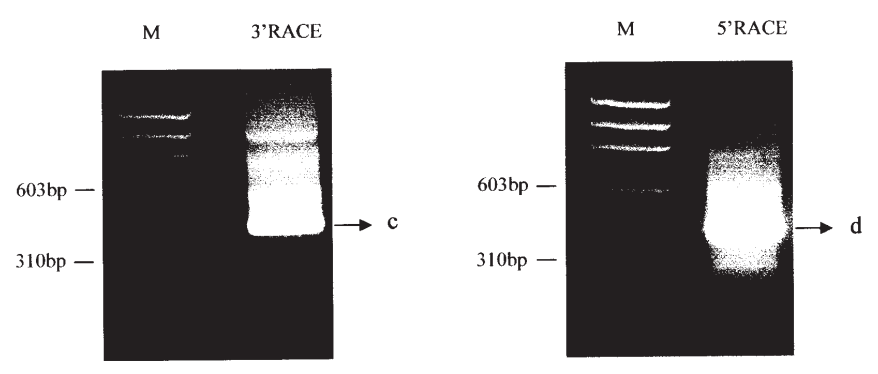

Figure 2. 3' and 5' RACE analysis for JS-1 and JS-2. For JS-1, bands a and b were generated by the $3^{\prime}$ RACE and 5' RACE reactions respectively. For JS-2, bands c and d were produced as the 3' RACE and 5' RACE products. Details of the reactions are described in Materials and methods. M, molecular size marker ( $\varphi$ 174/HaeIII cut).

were transfected using a mixture composed of $1 \mu \mathrm{g}$ plasmid: $6 \mu 1$ FuGene 6 (Roche Diagnostics) transfection reagent. Seventy-two hours after transfection, cells were re-plated and selected with $300 \mu \mathrm{g} / \mathrm{ml} \mathrm{G} 418$ (JRH Biosciences) for 2 weeks. JS-1 and JS-2 transfected cells were then harvested by trypsinization to confirm expression of JS-1 and JS-2 genes by RT-PCR as described in the previous section using $\beta$-actin expression as control.

Cell growth assay. Parental NIH 3 T3 $\left(1 \times 10^{5}\right)$ and NIH 3 T3 cells transfected with: a) pcDNA3.1(-) vector only (3T3/vec); b) JS-1 (3T3/JS-1); and c) pcDNA3.1-H-rasV12 (3T3/ras) were grown in $75 \mathrm{~cm}^{2}$ culture flasks with DMEM medium supplemented with $10 \%$ FBS and with or without the addition of G418. Cells were trypsinised and counted using a hemocytometer (Boeco, Germany) on indicated days by the dyeexclusion method. When the cells were in a log growth phase, the population doubling time $(\mathrm{dt})$ was determined by the formula $\mathrm{dt}=\lg 2 / \lg \left(\mathrm{Ct} / \mathrm{C}_{0}\right) \times \mathrm{t}$, where $\mathrm{t}$ is the time between cell counts $\mathrm{Ct}$ and $\mathrm{C}_{0}, \mathrm{C}_{0}$ is the initial count, and $\mathrm{Ct}$ is the count after time $\mathrm{t}(14)$.

Foci formation and soft-agar assay. For the foci formation assay, $1 \times 10^{4}$ of parental NIH 3T3 cells, 3T3/vec cells, 3T3/ JS-1 cells and 3T3/ras cells were seeded in 6-well plates and grown to confluence. The cells were maintained in DMEM medium supplemented with 10\% FBS, with or without G418. The medium was replaced with fresh medium every 3 days. The cells were stained with methylene blue after 1 day, 3 days and 14 days for observation. For the soft-agar assay, the 


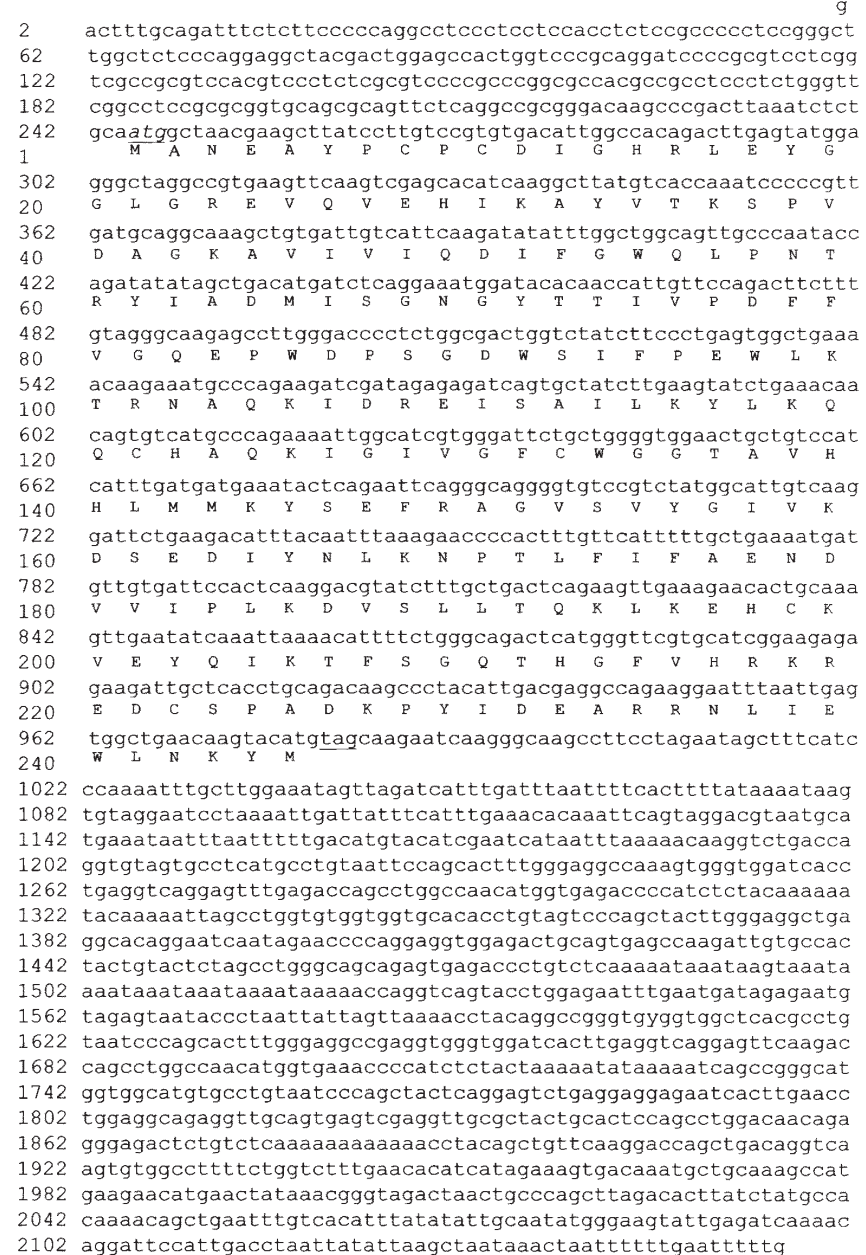

B

5

65
20

2025
40

185

60

245
80

305

100

100
365

365
120

120
425

140

485

160

545

180

605
200

200
665

665
220

725

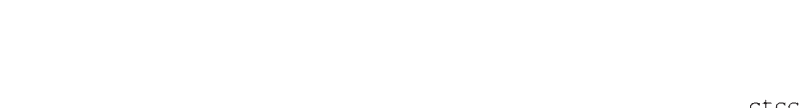

$\underset{\mathrm{M}}{\text { gcgatggagggaggaggaggtatacccctagaaacacttaaagaagaaagtcagtcaaga }}$ catgttctacctgcaagttttgaagtcaacagtttgcagaaaagcaactgggggttctta

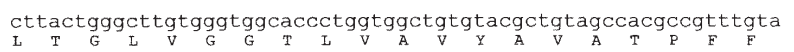

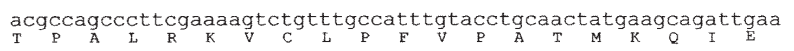

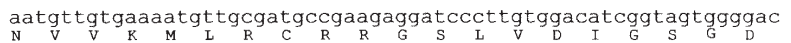

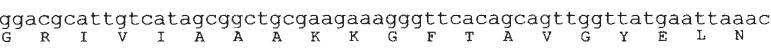

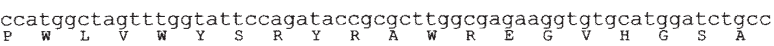

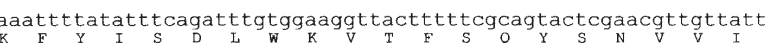
ttcggtgtgcctcagatgatgctgcagttggagaagaaact.tgaacgtgaacttgaggat $\begin{array}{lllllllllllllllllll}G & V & P & Q & M & M & L & Q & L & E & K & K & L & E & R & E & L & E & D\end{array}$

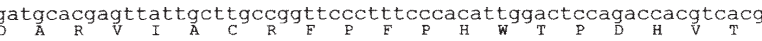
ggggaggggatagacacagtgtgggcatatgatgcaagcacttttagaggccgtgaaaag aggccctgtacatcgatgcatttccagctgcccattcaagcataaactttactgggagtg tttttctgaaatattgtagtcttccetgatcttgtagagacttacagctgtgtccttagc aaaggagcataattgtctttggtttggaatgagaaattactattactttccttaactgtt ggagaaaacaaacgaagaaaaacaggtagatttaaaatctgcttttgatgctattttct aaattgtacttactgcctttccatgcacctggatgcatgaaaagatgaataagtgat tcatggttatgg tagga tcatggttatgggtaggaazataagatgccaatagctcttcacattataaacaatatg agtatcctataacttgttcatacttaagttgtatctcttccttttgtact.catggc aaattaatttctaaaggattcagagaggcgtttatattttataacatttattagaaat atttgttccaccactagattactgtattttatggaatctaagctgtatatgtg tacatt tgtatacatgtatgtgtaaatgtaagcctgacgtgggttcagattccagttttgtcatca cactgggataatggtacacataacagtggagtggggaccaatttctaaaactcatggca ctagtctttggtccataaatggtgtttgttattttagacactgagaaaaatcttattca cagagttgcagattatttctgctagtcacttttttatttcttgagagctgccactcatt eat acctttgacotga ttgagtcattcgtacttatcacagaaaagaattgaactcccagtcatacacctgtaactg aaataccaaactgtcttaatggagatgtaatgaagtaagatggtcacatctttaactaaa cttataaaattg

Figure 3. (A) Nucleotide and predicted amino acid sequence of JS-1 based on 5' and 3' RACE analysis. The translation initiation codon (ATG) is underlined and italicized and the stop codon (TAG) are underlined. (B) Nucleotide and predicted amino acid sequence of JS-2 based on 5' and 3' RACE analysis. The translation initiation codon (ATG) is underlined and italicized and the stop codon (TAA) are underlined.

procedures were followed as previously described (15). Briefly, $2 \times 10^{4}$ parental NIH $3 \mathrm{~T} 3$ and transfected cells were suspended in $2.5 \%$ agar containing $20 \%$ 2X DMEM, 50\% DMEM, $10 \%$ FBS and overlaid with the same $2.5 \%$ agar mixture. Each soft-agar preparation was then incubated at $37^{\circ} \mathrm{C}$ for 16 days. The colony formation in each preparation with the clones having $>20$ cells were observed under microscope.

Tumorigenicity test. Approximately $1 \times 10^{6} 3 \mathrm{~T} 3 / \mathrm{JS}-1$ cells were subcutaneously injected into each flank of five female athymic nude mice after selection in G418 for 14 days. Parental NIH 3 T3 cells, 3T3/vec cells and 3T3/ras cells were also subcutaneously injected into athymic nude mice and served as controls. Formation of subcutaneous tumor was monitored for 30 days. The tumors were dissected and fixed in formalin for histopathological examination. Total RNAs and cDNAs of the parental NIH 3T3 cells, 3T3/vec cells, 3T3/JS-1 cells and the subcutaneous tumors were prepared, and the level of JS-1 expression was examined on the samples as described in the previous sections using GAPDH expression as the control.

Sequencing analysis. After confirming the transforming capacity of JS-1 overexpression in NIH 3 T3 cells, detection of polymorphism and mutation in coding sequence of JS-1 were investigated by direct sequencing on the RT-PCR products generated by the primers $8809-\mathrm{b}$ and $8809-\mathrm{c}$ of JS-1 from cDNA samples of NE3, ESCC cell lines (SLMT-1, HKESC-3, KYSE 30, 150, 180, 410, 450, 510 and 520) and 6 pairs of ESCC tissue specimens and their corresponding non-tumor tissues using ABI 310 Genetic Analyzer (Applied Biosystems).

Bioinformatics analysis. Nucleic acid and amino acid homology searches were performed using basic local alignment tool (BLAST) software in National Centre of Biotechnology Information (NCBI). ScanProsite (http://au.expasy.org) was used to scan protein sequence of JS-1 and JS-2 for the occurrence of pattern available in the PROSITE database. BDS-PRED was used to predict the DNA binding probability of JS-1 and JS-2 (http://gibk26.bse.kyutech.ac.jp/jouhou/ jouhoubank.html).

\section{Results}

Rapid amplification of $c D N A$ ends (RACE). Fig. 2 shows the products of $3^{\prime}$ and 5' RACE analysis. For JS-1, PCR bands 


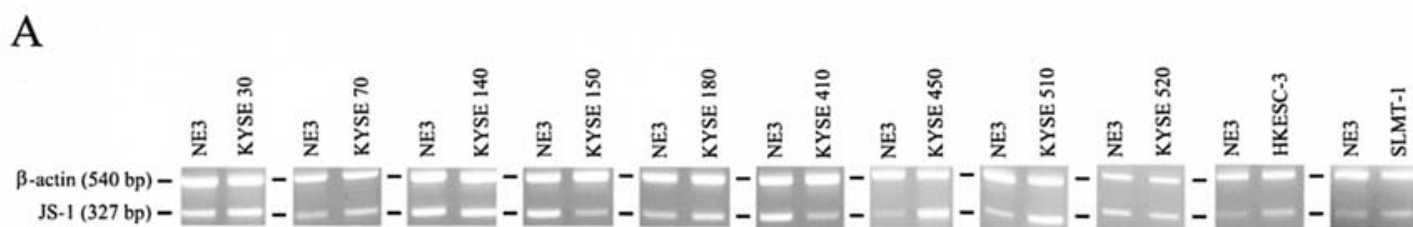

B
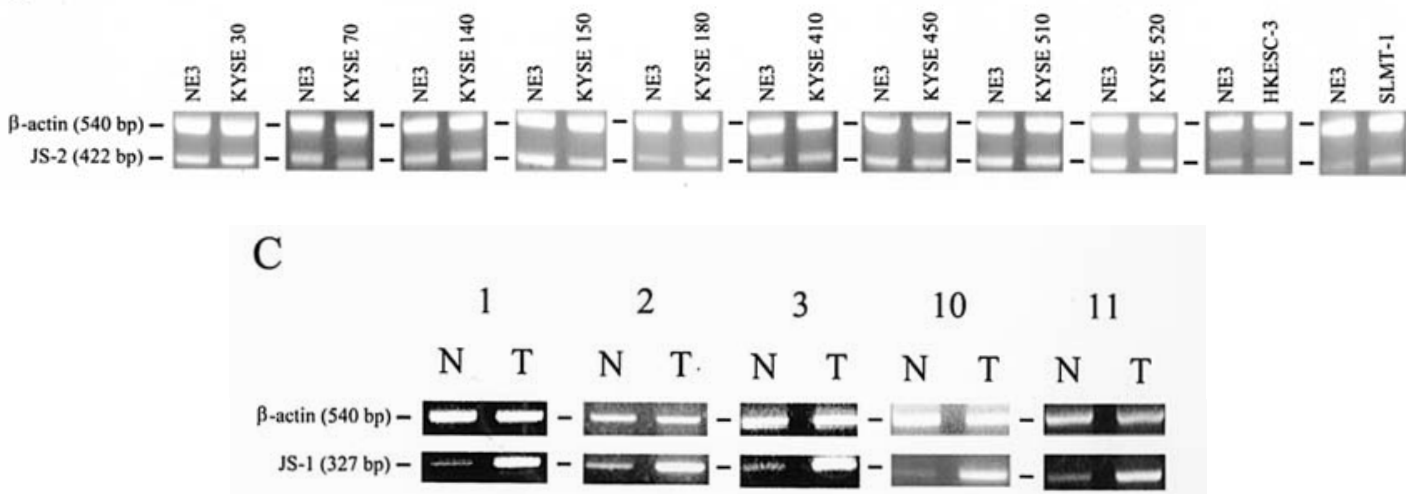

$\mathrm{D}$

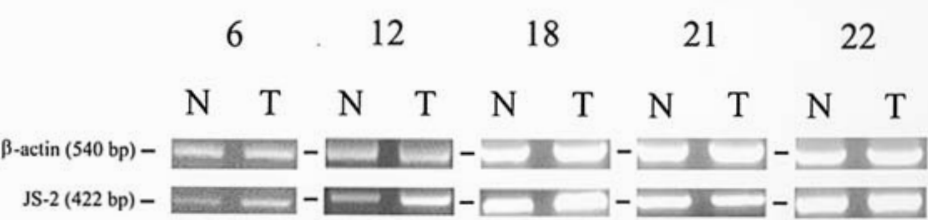

$\mathrm{E}$

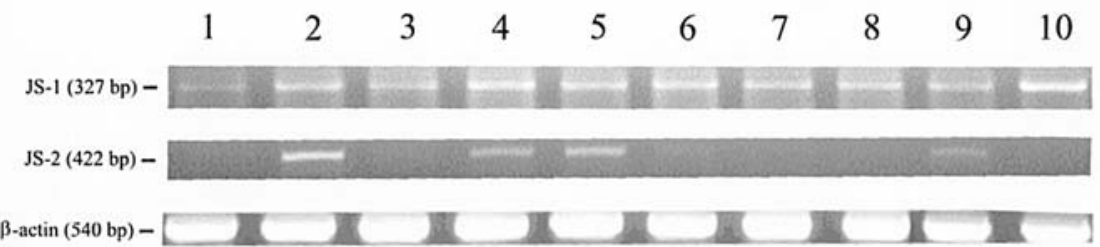

Figure 4. Expression study of JS-1 and JS-2 in human ESCC cell lines and tissue specimens. Results of semi-quantitative RT-PCR analysis for JS-1 and JS-2 was performed on ESCC cell lines as shown in (A) and (B) respectively. NE3 represents non-tumor epithelial cell line and B-actin expression was used as an internal control. ESCC cell lines KYSE 30, 450, 510, HKESC-3 and SLMT-1 show overexpression of JS-1 and only KYSE 180 and SLMT-1 overexpress JS-2. Representative examples of semi-quantitative RT-PCR analysis for JS-1 and JS-2 expression in human ESCC specimens as shown in (C) and (D) respectively. $\mathrm{N}$, corresponding non-tumor tissue; T, ESCC tissue. The number above each sample pair represents the patient no. shown in Table I. Expression analysis of JS-1 and JS-2 in multiple tissue cDNA (MTC) panel is shown in (E). All the organs studied show JS-1 expression with relatively lower level of expression found in the esophagus. JS-2 was only expressed in the stomach, ileocecum, jejunum and expression was relatively lower in the rectum. Lanes 1-10: 1, esophagus; 2, stomach; 3, duodenum; 4, ileocecum; 5, jejunum; 6, colon (ascending); 7, colon (descending); 8, colon (transverse); 9 , rectum; 10, liver.

(products a and b) were generated from the PCR of each $3^{\prime}$ and 5' RACE reactions respectively. PCR products $\mathrm{c}$ and $\mathrm{d}$ were produced from the $3^{\prime}$ and 5' RACE reactions of JS-2. The RACE products of JS- 1 and JS-2 were then sequenced to determine the $3^{\prime}$ and $5^{\prime}$ cDNA sequences of the two genes. Fig. 3 shows the full-length sequences of JS-1 and JS-2 cDNA respectively, based on the RACE analysis together with the predicted amino acid sequence and the $3^{\prime}$ and 5 ' non-coding sequences. The first ATG codon for JS-1 and JS-2 are at positions 245 and 8 respectively. They are associated with a Kozak sequence and are therefore deduced to be the start codons. The sequence that surrounds the start codon in JS-1 and JS-2 has a consensus sequence for initiation of translation by eukaryotic ribosomes with a purine at position -3 and a guanine following the ATG codon (16). The JS-1 is composed of 2156 nucleotides with 738 bp of coding sequence, 1174 bp of $3^{\prime}$ and 244 bp of 5' non-coding sequences. JS-1 was predicted to encode a novel protein of 245 amino acids that could not be matched with any known protein sequence in SwissProt using the BLAST search program that is available from the National Center for Biotechnology Information (http://www.ncbi.nlm.nih.gov). The amino acid sequence did not contain any well-characterized functional motifs when it was matched against the e-Motif search program that is available from Stanford University or the Motif Scan program available in the Institute for Chemical Research, Kyoto University which matches against the PROSITE patterns. When the JS-1 amino acid sequence was scanned against the PROSITE database using the ScanProsite program that is available in the ExPASy (expert protein analysis system) 
Table I. Summary of JS-1 and JS-2 expression studies and clinical data of ESCC patients.

\begin{tabular}{|c|c|c|c|c|c|c|}
\hline Patient no. & Age/sex & Histopathological type & Tumor stage & Histological stage & JS-1 expression & JS-2 expression \\
\hline 1 & 49/M & $\mathrm{SCC}(\mathrm{M})$ & $\mathrm{T}_{4} \mathrm{~N}_{1} \mathrm{M}_{1}$ & IV & $\uparrow$ & ND \\
\hline 2 & $57 / \mathrm{M}$ & $\operatorname{SCC}(\mathrm{W})$ & $\mathrm{T}_{3} \mathrm{~N}_{1} \mathrm{M}_{0}$ & III & $\uparrow$ & ND \\
\hline 3 & $60 / \mathrm{M}$ & $\mathrm{SCC}(\mathrm{M})$ & $\mathrm{T}_{3} \mathrm{~N}_{1} \mathrm{M}_{1}$ & IV & $\uparrow$ & ND \\
\hline 4 & $73 / \mathrm{M}$ & $\mathrm{SCC}(\mathrm{P})$ & $\mathrm{T}_{3} \mathrm{~N}_{1} \mathrm{M}_{0}$ & III & $\uparrow$ & ND \\
\hline 5 & $74 / \mathrm{M}$ & $\operatorname{SCC}(\mathrm{M})$ & $\mathrm{T}_{3} \mathrm{~N}_{0} \mathrm{M}_{0}$ & II & - & ND \\
\hline 6 & 47/M & $\operatorname{SCC}(\mathrm{M})$ & $\mathrm{T}_{3} \mathrm{~N}_{1} \mathrm{M}_{0}$ & III & $\downarrow$ & $\uparrow$ \\
\hline 7 & $59 / \mathrm{M}$ & $\mathrm{SCC}(\mathrm{M})$ & $\mathrm{T}_{3} \mathrm{~N}_{0} \mathrm{M}_{0}$ & II & $\uparrow$ & - \\
\hline 8 & $68 / \mathrm{M}$ & $\mathrm{SCC}(\mathrm{M})$ & $\mathrm{T}_{3} \mathrm{~N}_{0} \mathrm{M}_{0}$ & II & $\uparrow$ & - \\
\hline 9 & $45 / \mathrm{M}$ & $\mathrm{SCC}(\mathrm{P})$ & $\mathrm{T}_{4} \mathrm{~N}_{1} \mathrm{M}_{0}$ & III & $\uparrow$ & - \\
\hline 10 & $74 / \mathrm{M}$ & $\mathrm{D}$ & $\mathrm{T}_{0} \mathrm{~N}_{0} \mathrm{M}_{0}$ & NA & $\uparrow$ & $\downarrow$ \\
\hline 11 & $66 / \mathrm{M}$ & $\mathrm{SCC}(\mathrm{M})$ & $\mathrm{T}_{3} \mathrm{~N}_{1} \mathrm{M}_{0}$ & III & $\uparrow$ & $\downarrow$ \\
\hline 12 & $71 / \mathrm{M}$ & $\mathrm{D}$ & $\mathrm{T}_{0} \mathrm{~N}_{0} \mathrm{M}_{0}$ & N.A. & $\uparrow$ & $\uparrow$ \\
\hline 13 & $58 / \mathrm{M}$ & $\operatorname{SCC}(\mathrm{M})$ & $\mathrm{T}_{3} \mathrm{~N}_{0} \mathrm{M}_{0}$ & II & $\uparrow$ & - \\
\hline 14 & $74 / \mathrm{M}$ & (Post CTRT) & NT & NA & $\downarrow$ & - \\
\hline 15 & $57 / \mathrm{M}$ & $\mathrm{SCC}(\mathrm{W})$ & $\mathrm{T}_{4} \mathrm{~N}_{0} \mathrm{M}_{0}$ & III & - & - \\
\hline 16 & $63 / \mathrm{M}$ & MEC & $\mathrm{T}_{3} \mathrm{~N}_{1} \mathrm{M}_{0}$ & III & - & - \\
\hline 17 & $57 / \mathrm{M}$ & $\operatorname{SCC}(\mathrm{M})$ & $\mathrm{T}_{3} \mathrm{~N}_{0} \mathrm{M}_{0}$ & II & $\uparrow$ & - \\
\hline 18 & $77 / \mathrm{M}$ & $\mathrm{SCC}(\mathrm{W})$ & $\mathrm{T}_{4} \mathrm{~N}_{1} \mathrm{M}_{0}$ & III & - & $\uparrow$ \\
\hline 19 & $70 / \mathrm{M}$ & $\mathrm{SCC}(\mathrm{M})$ & $\mathrm{T}_{3} \mathrm{~N}_{0} \mathrm{M}_{1 \mathrm{~b}}$ & IV & - & - \\
\hline 20 & $71 / \mathrm{M}$ & $\mathrm{SCC}(\mathrm{P})$ & $\mathrm{T}_{3} \mathrm{~N}_{0} \mathrm{M}_{0}$ & II & $\downarrow$ & - \\
\hline 21 & $74 / \mathrm{M}$ & $\mathrm{SCC}(\mathrm{M})$ & $\mathrm{T}_{3} \mathrm{~N}_{1} \mathrm{M}_{0}$ & III & $\downarrow$ & - \\
\hline 22 & $66 / \mathrm{M}$ & $\mathrm{SCC}(\mathrm{W})$ & $\mathrm{T}_{3} \mathrm{~N}_{0} \mathrm{M}_{1 \mathrm{a}}$ & IV & $\downarrow$ & - \\
\hline 23 & $76 / \mathrm{M}$ & $\mathrm{SCC}(\mathrm{M})$ & $\mathrm{T}_{3} \mathrm{~N}_{0} \mathrm{M}_{0}$ & II & $\uparrow$ & - \\
\hline 24 & $57 / \mathrm{M}$ & $\mathrm{SCC}(\mathrm{W})$ & $\mathrm{T}_{3} \mathrm{~N}_{0} \mathrm{M}_{0}$ & II & - & - \\
\hline 25 & $70 / \mathrm{M}$ & $\mathrm{SCC}(\mathrm{W})$ & $\mathrm{T}_{3} \mathrm{~N}_{0} \mathrm{M}_{0}$ & II & $\uparrow$ & - \\
\hline 26 & $60 / \mathrm{M}$ & $\mathrm{SCC}(\mathrm{P})$ & $\mathrm{T}_{3} \mathrm{~N}_{1} \mathrm{M}_{0}$ & III & $\uparrow$ & - \\
\hline 27 & $68 / \mathrm{M}$ & $\mathrm{SCC}(\mathrm{P})$ & $\mathrm{T}_{3} \mathrm{~N}_{1} \mathrm{M}_{0}$ & III & $\downarrow$ & - \\
\hline
\end{tabular}

SCC, squamous cell carcinoma; MEC, mucoepidermoid carcinoma; Post CTRT, patient received chemoradiotherapy before operation; D, dysplasia; (W), well differentiated type of tumor; (M), moderately differentiated type of tumor; (P), poorly differentiated type of tumor; ND, RT-PCR analysis for expression was not done because of insufficient tissue availability; NA, not applicable; NT, non-tumor; $\uparrow$, upregulation; $\downarrow$, down-regulation; -, no change in expression.

proteomics server of the Swiss Institute of Bioinformatics, JS-1 protein consisted of two casein kinase II phosphorylation sites at the amino acid residues 37-40 (S-P-V-D) and 223-226 (S-P-A-D), one protein kinase $\mathrm{C}$ phosphorylation site at amino acid residues 191-193 (T-Q-K), one tyrosine kinase phosphorylation site at the amino acid residues 159-165 (K-D-S-ED-I-Y), one tyrosine sulfation site at amino acid residues 158-172 (V-K-D-S-E-D-I-Y-N-L-K-N-P-T-L) and two Nmyristoylation sites at amino acid residues 68-73 (G-N-GY-T-T) and 209-214 (G-Q-T-H-G-F). JS-2 is composed of 1871 nucleotides with $702 \mathrm{bp}$ of coding sequence, $1133 \mathrm{bp}$ of $3^{\prime}$ and $7 \mathrm{bp}$ of 5 ' non-coding sequences. JS-2 was predicted to encode a novel protein of 233 amino acids that could not be matched with any known protein sequences in SwissProt. ScanProsite analysis found that JS-2 protein was found to contain 2 casein kinase II phosphorylation sites at amino acid residues 11-14 (T-L-K-E) and 91-94 (S-L-V-D), four protein kinase $\mathrm{C}$ phosphorylation sites at amino acid residues 11-13 (T-L-K), 74-76 (T-M-K), 138-140 (S-A-K) and 213-215 (T-F-R), four $\mathrm{N}$-myristoylation sites at amino acid residues
42-47 (G-L-V-G-G-T), 46-51 (G-T-L-V-A-V), 96-101 (G-SG-D-G-R) and 134-139 (G-V-H-G-S-A), and one cAMPand cGMP-dependent protein kinase phosphorylation site at amino acid residues 88-91 (R-R-G-S).

$J S-1$ and JS-2 expression in human ESCC cell lines, tissue specimens and corresponding non-tumor tissues. Expression of JS-1 and JS-2 novel genes was examined by semi-quantitative RT-PCR. The ratio of JS-1 and JS-2 expression level in ESCC cell lines and tissue specimens was calculated as described in Materials and methods. The expression was regarded as upregulation when the [(JS-1 or JS-2/ß-actin, tumor)]/[(JS-1 or JS-2/ß-actin, paired non-tumor)] ratio was $>1.2$; between 0.8 and 1.2 was regarded as no change; and $<0.8$ was regarded as down-regulation (17). Fig. 4A shows 45\% (5/11; KYSE 30, 450,510 , HKESC-3 and SLMT-1) of ESCC cell lines overexpressing JS-1 gene and according to Fig. 4B that only $18 \%$ (2/11; KYSE 180 and SLMT-1) of ESCC cell lines overexpressed JS-2 gene. Fig. 4C and D show the representative examples of JS-1 and JS-2 overexpression in ESCC specimens. 
As a whole, 55\% (15/27) of ESCC specimens overexpressed JS-1 gene and only 14\% (3/22) of specimens overexpressed JS-2 gene. Twenty-seven ESCC specimens were studied for JS-1 expression and only 22 specimens were studied for JS-2 expression because of insufficient ESCC tissue availability. The histopathological features and the expression patterns of JS-1 and JS-2 cases studied are summarized in Table I. According to Fig. 4E, JS-1 was expressed in all the normal tissues of the gastrointestinal system with esophagus expressing relatively lower level than other gastrointestinal organs studied. JS-2 was expressed only in the stomach, ileocecum, jejunum and expression level was relatively lower in the rectum (Fig. 4E).

Transforming properties of JS-1 and JS-2 on NIH 3 T3 cells. In order to study the roles of JS-1 and JS-2 overexpression in relation to their transforming potentials in normal cells, in vitro studies of colony formation in soft agar, foci formation, and growth rate were performed. 3T3/JS-1 cells and 3T3/ras cells formed colonies in soft agar but colony formation was not observed in parental NIH 3T3 cells, 3T3/vec cells and 3T3/JS-2 cells (Fig. 5A). Thus hereafter, we focused on the overexpression of JS-1 and subsequent tests were only performed on JS-1. To determine whether JS-1 overexpression affected the growth of transfected cells, parental NIH 3T3 cells, 3T3/vec cells, 3T3/JS-1 cells and 3T3/ras cells were seeded in culture flasks containing DMEM medium supplemented with $10 \%$ FBS and with or without addition of G418. According to the growth curve (Fig. 5B) 3T3/JS-1 cells proliferated as rapidly as the positive control cells (3T3/ras) and the doubling time was reduced from $24.1 \mathrm{~h}$ in parental NIH 3T3 cells to $17.2 \mathrm{~h}$ in 3T3/JS-1 cells. Moreover, 3T3/JS-1 cells and 3T3/ras cells lost their contact inhibition when they reached confluent growth and formed detectable foci (Fig. 5C). In contrast, the parental NIH $3 \mathrm{~T} 3$ cells and $3 \mathrm{~T} 3 / \mathrm{vec}$ cells exhibited contact inhibition and did not form detectable foci.

Tumorigenicity test. To investigate the tumorigenic potential of JS-1 when it is overexpressed, 3T3/JS-1 cells were subcutaneously injected into five athymic nude mice. 3T3/JS-1 cells induced subcutaneous tumor formation at the site of injection in all the mice tested and 3T3/vec cells did not form any subcutaneous tumors (Fig. 6A). A histological analysis of the tumor formed by $3 \mathrm{~T} 3 / \mathrm{JS}-1$ cells showed a hypercellular tumor which is composed of spindle tumor cells with prominent nucleoli and frequent mitotic figures (Fig. 6B). The tumor cells infiltrated through the skeletal muscles. The overall features are those of a malignant tumor, consistent with a high grade sarcoma. To confirm the expression level of JS-1 in the subcutaneous tumors and the transfected cells, RT-PCR was performed on the parental NIH 3T3, 3T3/vec, and $3 \mathrm{~T} 3 / \mathrm{JS}-1$ cells, and on the subcutaneous sarcoma. 3T3/JS-1 cells and the subcutaneous sarcoma showed overexpression of JS-1 compared with the controls (Fig. 6C).

Sequencing analysis. From direct DNA sequencing analysis on the coding sequence of JS-1 no mutation was detected in NE3, ESCC cell lines (SLMT-1, HKESC-3, KYSE 30, 150, $180,410,450,510$ and 520) or in the selected ESCC tissue specimens and their corresponding non-tumor tissues. The

A

(a)

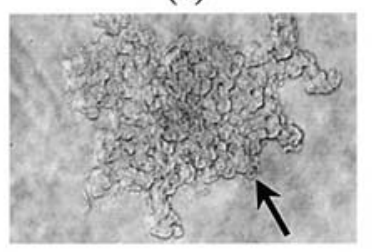

(c)

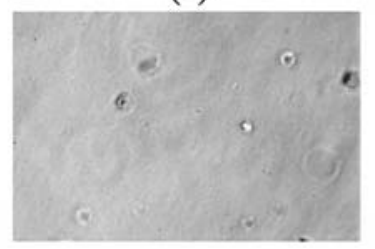

B

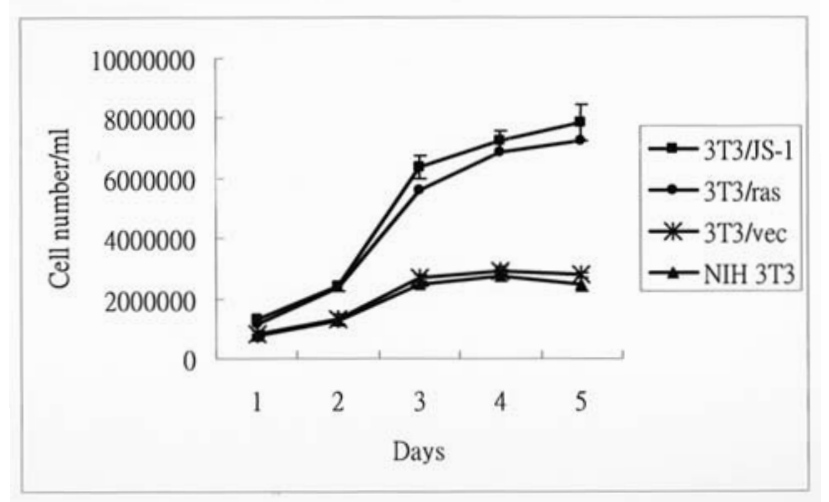

$\mathrm{C}$
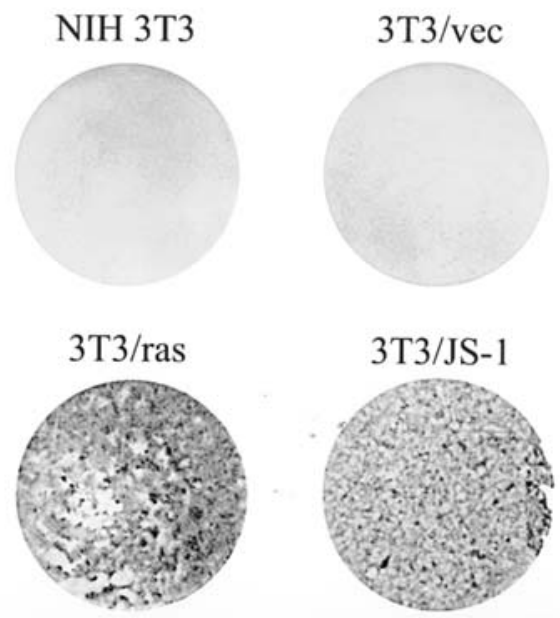

Figure 5. (A) Anchorage-independent growth of NIH 3 T3 cells transfected with (a) JS-1, (b) JS-2, (c) pcDNA3.1(-) vector only and (d) pcDNA3.1-Hras V12. Colonies (arrows) were formed in NIH 3T3 cells transfected with JS-1 and pcDNA3.1-H-ras V12 but not in cells transfected with JS-2 and mock vector. Photographs were taken after 16 days of cell growth in soft agar. Original magnification x200. (B) Growth curves of parental NIH 3 T3 cells, 3T3/JS-1 cells, 3T3/vec cells and 3T3/ras cells. Cells were grown under conditions as described in Materials and methods. Cells were counted on indicated days with a haemocytometer. All results are the means of triplicate experiments and the standard deviations are indicated by the standard bars. (C) Anchorage-dependent growth assay to show foci formation in parental NIH 3T3, 3T3/vec, and 3T3/ras cells, and 3T3/JS-1 cells at day 14 after seeding of cells. Foci formation could be observed in NIH 3T3 cells transfected with pcDNA3.1-H-ras V12 and JS-1 but not in the parental NIH $3 \mathrm{~T} 3$ cells and those transfected with the mock vector. 
A (a)

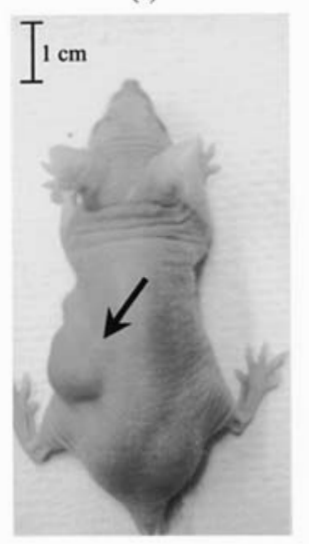

(b)

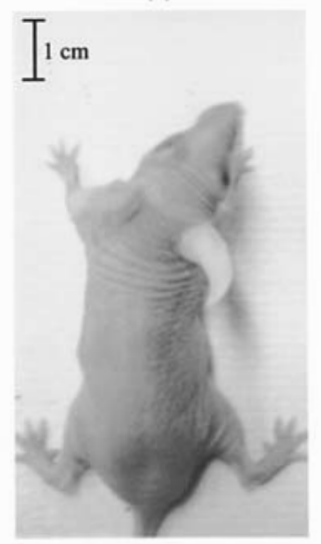

B

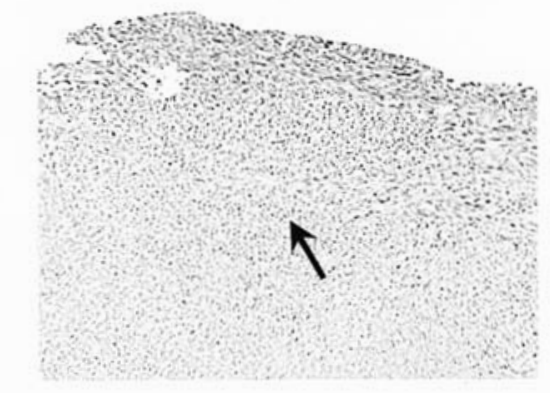

C

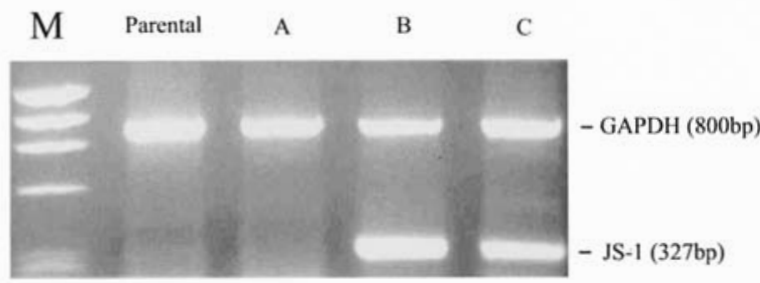

Figure 6. (A) Tumorigenicity test using athymic nude mice with subcutaneous injection of (a) 3T3/JS-1 and (b) 3T3/vec cells. Subcutaneous formation of tumor mass (arrow) could be observed in the mouse injected with 3T3/JS-1 cells but not in the mock control after 30 days of injection. (B) Histological analysis on the subcutaneous tumor formed in athymic nude mice by the injection of 3T3/JS-1 cells showing the morphology of high grade sarcoma (arrow). Hematoxylin and eosin staining; original magnification x200. (C) Semi-quantitative RT-PCR analysis of JS-1 expression in parental NIH 3T3 cells (parental), NIH 3T3 cells transfected with (A) pcDNA3.1(-) vector only, (B) JS-1, and (C) subcutaneous tumor tissue from athymic nude mouse. GAPDH expression served as the internal control. M, molecular size marker ( $\varphi$ 174/HaeIII cut).

coding sequences worked out were identical to that of NE3, a non-tumor esophageal epithelial cell line, as well as to the relevant sequence previously published in the GenBank (LOC 134147).

\section{Discussion}

ESCC is an aggressive cancer that is characterized by a high mortality rate and geographic differences in incidence (1). Despite advances in multimodality treatment, the 5-year survival rate of ESCC remains $<10 \%$ (4). Identification of molecular therapeutic targets may be important in improving the survival of patients. Genetic alterations involved in the development or progression of ESCC have been studied (5), but a complete picture about the molecular pathogenesis of ESCC is still largely unknown. Thus, it is important to identify novel genes associated with ESCC and understand the underlying mechanisms of this disease.

The completion of the human genome project has resulted in a vast amount of genomic information and the roles of many identified genes remain unknown. In the present study, we have studied the expression of two novel genes, JS-1 and JS-2, located on chromosome $5 \mathrm{p} 15.2$ which are upstream to $\delta$ catenin gene and have not been studied previously for their roles in the molecular pathogenesis of ESCC. The complete cDNA sequence of JS-1 and JS-2 was determined by 5 ' and 3' RACE study and the expression pattern of JS-1 and JS-2 was examined by RT-PCR, which is a fast and convenient method for gene expression study. JS-1 was overexpressed in $45 \%(5 / 11)$ of ESCC cell lines and in 55\% (15/27) of ESCC tissues. Several other genes implicated in ESCC carcinogenesis have also been reported to have high levels of overexpression, e.g. cyclin D1, 63\% (18) and EphA2, 50\% (19). JS-1 overexpression induced tumorigenic transformation in NIH 3T3 cells through three main observations: formation of transformed foci on a monolayer of cells, anchorage-independent growth in soft agar, and tumor formation in nude mice. Soft agar assay is a stringent assay for detecting malignant transformation of cells and was developed by Hamburger and Salmon (20). The correlation between anchorage-independent growth of cells in semi-solid medium and tumorigenicity was first reported by Freedman and Shin (21). Later, Shin et al (22) showed that the only cellular property repeatedly linked with tumorigenicity in nude mice is the ability of transformed cells to proliferate in vitro in the absence of anchorage. Thus the results indicate that JS-1 overexpression could play an oncogenic role in ESCC. Several genes overexpressed and implicated in various cancers have also shown to induce tumors in nude mice. Examples include overexpression of SKP2 (S-phase kinase-associated protein 2) which results in colony formation in soft agar and tumor formation in athymic nude mice (23) and it is overexpressed in ESCC (24), lymphomas (25) and oral squamous cell carcinoma (23). Overexpression of MDM2 has been shown to confer tumorigenicity in nude mice (26) and it is overexpressed in $22 \%$ of esophageal cancers (27).

In the present study, overexpression of JS-1 was observed in $22 \%(6 / 27)$ of patients with stage II tumor, $18 \%(5 / 27)$ of patients with stage III tumor and in $7 \%(2 / 27)$ of patients with stage IV tumor. It was reported that ESCC patients with stage II tumors have an approximate survival rate of 30-40\% (28). The higher percentage of JS-1 expression in stage II and III tumors may suggest its significance in the middle stages of the disease and its expression can be lost or reduced as the disease becomes more aggressive and develops metastatic potential. Ebihara et al (29) reported higher number of ESCC patients with $\mathrm{E} 2 \mathrm{~F} 1$ overexpression in stage II than in the later stages. Higher percentages of genetic alterations in stage III than in stage IV ESCC were also reported in cyclin D1 (30) amplification. Of the 15 cases overexpressing JS-1, 73\% $(11 / 15), 53 \%(8 / 15)$ and $86 \%$ (13/15) are of tumor stage T3, No, M0 respectively, suggesting tumor infiltrating to adventitia but not involving lymph node and distant metastasis. Over- 
Table II. Bioinformatics analysis on JS-1 and JS-2 transcripts and proteins.

\begin{tabular}{lll}
\hline Search program & \multicolumn{1}{c}{ JS-1 } & JS-2 \\
\hline $\begin{array}{l}\text { NCBI-BLAST } \\
\text { (http://www.ncbi.nih.gov/BLAST) }\end{array}$ & No homology to known functional genes & No homology to known functional genes \\
ScanProsite Search & Two casein kinase II phosphorylation sites & Two casein kinase II phosphorylation sites \\
(http://au.expasy.org) & One protein kinase C phosphorylation & Four protein kinase C phosphorylation sites \\
& One tyrosine kinase phosphorylation site & Four N-myristoylation sites \\
& One tyrosine sulfation site & One cAMP- and cGMP-dependent protein \\
& Two N-myristoylation sites & kinase phosphorylation site
\end{tabular}

(http://gibk26.bse.kyutech.ac.jp/

jouhou/jouhoubank.html)

IntroProScan search

(http://www.ebi.ac.uk/InterProScan)

Esterase/lipase/thioesterase and

Sterile alpha motif (SAM)

expression of a few genes in ESCC have been significantly correlated to TNM clinical classification e.g. RhoA (31). A larger study is needed to correlate JS-1 expression to prognosis of this disease. Various molecular factors proposed as prognostic indicators of esophageal cancer include p53, mdm2, cyclin D1, EGFR and E-cadherin (32). Additional studies on JS-1 gene include identification of its promoter and regulatory elements to elucidate the mechanisms underlying its expression in normal esophagus and overexpression in esophageal cancer. In contrast, JS-2 gene was overexpressed in only $18 \%(2 / 11)$ of ESCC cell lines and 14\% (3/22) of ESCC tissues and its overexpression in NIH 3 T3 cells did not induce cellular transformation. Although it may not play a role in ESCC on its own but as a novel gene with no known functions, it will be useful to identify its role in normal cells in a future study.

Identification and characterization of genes whose expression is dramatically altered in tumor versus normal epithelium may be important in understanding the genetic events underlying cancer development. In the last couple of years, many novel genes have been identified in esophageal cancer which may play a role in the carcinogenesis of ESCC e.g. EC97 (33) and hRFI (34). RT-PCR studies and Northern blot analysis have shown that these genes have dysregulated expression at the transcriptional level in ESCC tissues. Our present study provides evidence of the involvement of a novel gene JS-1 located at chromosome $5 p$ in the molecular carcinogenesis of ESCC. To date, several known genes located on chromosome $5 p$ have been implicated in ESCC. These genes are the telomerase reverse transcriptase gene (35), uracil-DNA glycosylase 2 gene (36), SKP2 gene (24) and complement component 6 and component 7 genes (37). This suggests that genes located on chromosome $5 \mathrm{p}$ may be significant in the tumorigenesis of the esophagus and JS-1 was identified from the present study as being one of them. Thus, this region warrants further studies for its role in the development of ESCC.

Amplification of $5 p$ is of particular importance because other than in ESCC, genomic alterations in this region has also been implicated in various carcinomas of the breast, head and neck, lung, bladder, and cervix (38). The combined evidence suggests that this region may harbour oncogenes in different neoplasms. Since ESCC was used in the present study as a target to study JS-1 and JS-2 expression, it will also be useful to study their expression in other cancers. Therefore, it will be important to explore the pathways JS-1 plays a part in and to investigate its interactions with other genes in order to understand the roles of JS-1 in cancer formation.

Bioinformatics analysis on JS-1 and JS-2 transcripts and proteins are listed in Table II. No homology was found between JS-1 and JS-2 with known functional genes. SwissProt analysis of JS-1 revealed important kinase phosphorylation sites for protein kinase C, casein kinase II and tyrosine kinase. JS-1 could be involved in some physiological processes through these domains. The overexpression of JS-1 may lead to disorder of its downstream gene(s) and result in ESCC formation indirectly. Further studies are needed to determine exact mechanisms of JS-1 in the process of tumorigenesis of ESCC. A number of tyrosine kinases have been reported to have a relationship with cancer progression and patient prognosis in ESCC $(19,39)$. Focal adhesion kinase (FAK) and EphA2, receptor tyrosine kinase, are examples of tyrosine kinase reported to be implicated in ESCC. Overexpression of FAK has been linked to cell differentiation, tumor invasiveness, lymph node metastasis and poor prognosis (39). EphA2 overexpression has also been related to poor prognosis in ESCC (19).

To conclude, the present study investigated a novel human gene designated as JS-1, whose overexpression and transforming capacity in normal cells may play a role in the molecular pathogenesis of ESCC. Further studies on the functional roles of JS-1 in normal and tumor cells may identify novel target(s) for anti-cancer treatments in ESCC and other cancers. Our group is also investigating the anticancer effects of different herbal medicines in modulating the expression of crucial genes in different cancers (40-43). The involvement of JS-1 in ESCC will open a new chapter to study its therapeutic value on this line. 


\section{Acknowledgements}

We acknowledge the support by the Internal Competitive Research Grants (ICRG) of the Hong Kong Polytechnic University (grant no. A-PF03) to the work described in this report. C.H.C. is supported by the post of 'Research Associate' from the project of 'Catalytic asymmetric synthesis of bioactive derivatives and the investigation of their anti-cancer activities' kindly offered by Professor A.S.C.C. under the Areas of Excellence Scheme established by the University Grants Committee of the Hong Kong Special Administrative Region, P.R. China (Project No. AoE/P-10/01). This research work also forms part of the M.Phil. study of S.F.

\section{References}

1. Si HX, Tsao SW, Poon CS, Wang LD, Wong YC and Cheung AL: Viral load of HPV in esophageal squamous cell carcinoma. Int $\mathrm{J}$ Cancer 103: 496-500, 2003.

2. Koshy M, Esiashvilli N, Landry JC, Thomas CR Jr and Matthews RH: Multiple management modalities in esophageal cancer: epidemiology, presentation and progression, work-up, and surgical approaches. Oncologist 9: 137-146, 2004.

3. Yen CC, Chen YJ, Chen JT, et al: Comparative genomic hybridization of esophageal squamous cell carcinoma: correlations between chromosomal aberrations and disease progression/ prognosis. Cancer 92: 2769-2777, 2001.

4. Kwong D, Lam A, Guan X, Law S, Tai A, Wong J and Sham J: Chromosomal aberrations in esophageal squamous cell carcinoma among Chinese: gain of $12 \mathrm{p}$ predicts poor prognosis after surgery. Hum Pathol 35: 309-316, 2004

5. Lam AK: Molecular biology of esophageal squamous cell carcinoma. Crit Rev Oncol Hematol 33: 71-90, 2000.

6. Syrjänen KJ: HPV infections and oesophageal cancer. J Clin Pathol 55: 721-728, 2002.

7. Shai R, Shi T, Kremen TJ, et al: Gene expression profiling identifies molecular subtypes of gliomas. Oncogene 22: 4918-4923, 2003.

8. Burger MJ, Tebay MA, Keith PA, Samaratunga HM, Clements J, Lavin MF and Gardiner RA: Expression analysis of delta-catenin and prostate-specific membrane antigen: their potential as diagnostic markers for prostate cancer. Int J Cancer 100: 228-237, 2002.

9. Tang JC, Wan TS, Wong N, et al: Establishment and characterization of a new xenograft-derived human esophageal squamous cell carcinoma cell line SLMT-1 of Chinese origin. Cancer Genet Cytogenet 124: 36-41, 2001.

10. Hu YC, Lam KY, Law SY, et al: Establishment, characterization, karyotyping, and comparative genomic hybridization analysis of HKESC-2 and HKESC-3: two newly established human esophageal squamous cell carcinoma cell lines. Cancer Genet Cytogenet 135: 120-127, 2002.

11. Shimada Y, Imamura M, Wagata T, Yamaguchi $\mathrm{N}$ and Tobe T: Characterization of 21 newly established esophageal cancer cell lines. Cancer 69: 277-284, 1992.

12. Miyazono F, Metzger R, Warnecke-Eberz U, et al: Quantitative c-erbB-2 but not c-erbB-1 mRNA expression is a promising marker to predict minor histopathologic response to neoadjuvant radiochemotherapy in oesophageal cancer. $\mathrm{Br} \mathrm{J}$ Cancer 91: 666-672, 2004

13. Jin W, Wu L, Liang K, Liu B, Lu Y and Fan Z: Roles of the PI-3K and MEK pathways in Ras-mediated chemoresistance in breast cancer cells. Br J Cancer 89: 185-191, 2003.

14. Ma T, Zhu ZG, Ji YB, et al: Correlation of thymidylate synthase, thymidine phosphorylase and dihydropyrimidine dehydrogenase with sensitivity of gastrointestinal cancer cells to 5-fluorouracil and 5-fluoro-2'-deoxyuridine. World J Gastroenterol 10: 172-176, 2004.

15. Cowley S, Paterson H, Kemp P and Marshall CJ: Activation of MAP kinase is necessary and sufficient for PC 12 differentiation and for transformation of NIH 3T3 cells. Cell 77: 841-852, 1994.

16. Kozak M: An analysis of 5'-non-coding sequences from 699 vertebrate messenger RNAs. Nucleic Acids Res 15: 8125-8148, 1987.
17. Zhou C, Liu S, Zhou X, et al: Overexpression of human pituitary tumor transforming gene (hPTTG), is regulated by beta-catenin/ TCF pathway in human esophageal squamous cell carcinoma. Int J Cancer 113: 891-898, 2005.

18. Adelaide J, Monges G, Derderian C, Seitz JF and Birnbaum D: Oesophageal cancer and amplification of the human cyclin D gene CCND1/PRAD1. Br J Cancer 71: 64-68, 1995.

19. Miyazaki T, Kato H, Fukuchi M, Nakajima M and Kuwano H: EphA2 overexpression correlates with poor prognosis in esophageal squamous cell carcinoma. Int J Cancer 103: 657-663, 2003.

20. Hamburger A and Salmon SE: Primary bioassay of human myeloma stem cells. J Clin Invest 60: 846-854, 1977.

21. Freedman VH and Shin SI: Cellular tumorigenicity in nude mice: correlation with cell growth in semi-solid medium. Cell 3: 355-359, 1974.

22. Shin SI, Freedman VH, Risser R and Pollack R: Tumorigenicity of virus-transformed cells in nude mice is correlated specifically with anchorage independent growth in vitro. Proc Natl Acad Sci USA 72: 4435-4439, 1975

23. Gstaiger M, Jordan R, Lim M, Catzavelos C, Mestan J, Slingerland $\mathrm{J}$ and Krek W: Skp2 is oncogenic and overexpressed in human cancers. Proc Natl Acad Sci USA 98: 5043-5048, 2001.

24. Fukuchi M, Masuda N, Nakajima M, Fukai Y, Miyazaki T, Kato $\mathrm{H}$ and Kuwano $\mathrm{H}$ : Inverse correlation between expression levels of p27 and the ubiquitin ligase subunit Skp2 in early esophageal squamous cell carcinoma. Anticancer Res 24: 777-783, 2004.

25. Latres E, Chiarle R, Schulman BA, Pavletich NP, Pellicer A, Inghirami $G$ and Pagano M: Role of the F-box protein Skp2 in lymphomagenesis. Proc Natl Acad Sci USA 98: 2515-2520, 2001.

26. Zhang R, Wang H and Agrawal S: Novel antisense anti-MDM2 mixed-backbone oligonucleotides: proof of principle, in vitro and in vivo activities, and mechanisms. Curr Cancer Drug Targets 5: 43-49, 2005.

27. Morgan RJ, Newcomb PV, Hardwick RH and Alderson D: Amplification of cyclin D1 and MDM-2 in oesophageal carcinoma. Eur J Surg Oncol 25: 364-367, 1999.

28. Enzinger PC and Mayer RJ: Esophageal cancer. N Engl J Med 349: 2241-2252, 2003.

29. Ebihara Y, Miyamoto M, Shichinohe T, et al: Over-expression of E2F-1 in esophageal squamous cell carcinoma correlates with tumor progression. Dis Esophagus 17: 150-154, 2004.

30. Itami A, Shimada Y, Watanabe G and Imamura M: Prognostic value of p27(Kip1) and cyclin D1 expression in esophageal cancer. Oncology 7: 311-317, 1999.

31. Faried A, Nakajima M, Sohda M, Miyazaki T, Kato H and Kuwano H: Correlation between RhoA overexpression and tumour progression in esophageal squamous cell carcinoma. Eur J Surg Oncol 31: 410-414, 2005

32. Shimada Y, Imamura M, Watanabe G, Uchida S, Harada H, Makino $T$ and Kano M: Prognostic factors of oesophageal squamous cell carcinoma from the perspective of molecular biology. Br J Cancer 80: 1281-1288, 1999.

33. Lu J, Hu G, Wang X, Wu M and Liu Z: Cloning and characterization of a novel gene EC97 associated with human esophageal squamous cell carcinoma. Int J Mol Med 11: 243-247, 2003.

34. Sasaki S, Nakamura T, Arakawa H, Mori M, Watanabe T, Nagawa $\mathrm{H}$ and Croce $\mathrm{CM}$ : Isolation and characterization of a novel gene, hRFI, preferentially expressed in esophageal cancer. Oncogene 21: 5024-5030, 2002.

35. Yu HP, Xu SQ, Lu WH, Li YY, Li F, Wang XL and Su YH: Telomerase activity and expression of telomerase genes in squamous dysplasia and squamous cell carcinoma of the esophagus. J Surg Oncol 86: 99-104, 2004.

36. Xiong XD, Xu LY, Shen ZY, Cai WJ, Luo JM, Han YL and Li EM: Identification of differentially expressed proteins between human esophageal immortalized and carcinomatous cell lines by two-dimensional electrophoresis and MALDI-TOFmass spectrometry. World J Gastroenterol 8: 777-781, 2002.

37. Oka R, Sasagawa T, Ninomiya I, Miwa K, Tanii H and Saijoh K: Reduction in the local expression of complement component 6 (C6) and 7 (C7) mRNAs in oesophageal carcinoma. Eur J Cancer 37: 1158-1165, 2001.

38. Ueno T, Tangoku A, Yoshino S, et al: Gain of $5 \mathrm{p} 15$ detected by comparative genomic hybridization as an independent marker of poor prognosis in patients with esophageal squamous cell carcinoma. Clin Cancer Res 8: 526-533, 2002. 
39. Miyazaki T, Kato H, Nakajima M, et al: FAK overexpression is correlated with tumour invasiveness and lymph node metastasis in oesophageal squamous cell carcinoma. Br J Cancer 89: 140-145, 2003.

40. Chui CH, Lau FY, Tang JCO, et al: Activities of fresh juice of Scutellaria barbata and warmed water extract of Radix Sophorae Tonkinensis on anti-proliferation and apoptosis of human cancer cell lines. Int J Mol Med 16: 337-341, 2005.

41. Chui CH, Lau FY, Chan ASC, et al: Gleditsia sinensis fruit extract induced apoptosis involves changes of reactive oxygen species level, mitochondrial membrane depolarization and caspase 3 activation. Int J Mol Med 15: 539-543, 2005.
42. Teo ITN, Tang JCO, Chui CH, et al: Superoxide anion is involved in the early apoptosis mediated by Gleditsia sinensis extract. Int J Mol Med 13: 909-913, 2004.

43. Chui CH, Tang JCO, Lau FY, et al: Gleditsia sinensis fruit extract induced growth inhibition involves basic fibroblast growth factor and nitric oxide. Int J Mol Med 13: 169-173, 2004. 